\title{
Efficacy and toxicity of external-beam radiation therapy for localised prostate cancer: a network meta-analysis
}

\author{
Z Zhu ${ }^{1}$, J Zhang ${ }^{1}$, Y Liu ${ }^{1}$, M Chen ${ }^{1}, \mathrm{P}$ Guo ${ }^{2}$ and $\mathrm{K} \mathrm{Li}{ }^{*, 1}$ \\ ${ }^{1}$ Department of Public Health, Shantou University Medical College, No. 22 Xinling Road, Shantou, Guangdong 515041, China and \\ ${ }^{2}$ Department of Medical Statistics and Epidemiology, School of Public Health, Sun Yat-sen University, Guangzhou, Guangdong \\ 510080, China
}

Background: Many radiation regimens for treating prostate cancer have been used over the years, but which regimen is optimal for localised or locally advanced prostate cancer lacks consensus. We performed a network meta-analysis to identify the optimal radiation regimen.

Methods: We systematically reviewed data from 27 randomised controlled trials and could group seven radiation regimens as follows: low- and high-dose radiation therapy (LDRT and HDRT), LDRT + short- or long-term androgen deprivation therapy (LDRT + SADT and LDRT + LADT), HDRT + SADT, hypofractionated radiotherapy (HFRT), and HFRT + SADT. The main outcomes were overall mortality (OM), prostate-specific antigen (PSA) failure, cancer-specific mortality, and adverse events.

Results: For the network meta-analysis of 27 trials, LDRT + LADT and LDRT + SADT were associated with decreased risk of OM as compared with LDRT alone as was LDRT + LADT compared with HDRT. Apart from HFRT, all other treatments were associated with decreased risk of PSA failure as compared with LDRT. HFRT + SADT was associated with decreased risk of cancer-specific mortality as compared with HFRT, LDRT + SADT, HDRT, and LDRT.

Conclusions: HFRT + SADT therapy might be the most efficacious treatment but with worst toxicity for localised or locally advanced prostate cancer, and HDRT showed excellent efficacy but more adverse events.

In 2013, prostate cancer was diagnosed in 238590 Americans, and 29720 died of the disease (Siegel et al, 2013). Indeed, in 2008, the incidence and mortality rates of prostate cancer were the second and sixth highest among cancers for males in the world (Jemal et al, 2011). Approximately $90 \%$ of men have disease confined to the prostate gland (clinically localised disease). Prostate cancer incidence increased and disease-specific mortality rate decreased after the introduction of the prostate-specific antigen (PSA) blood test and with early interventions (Jemal et al, 2006).

Many methods for treating prostate cancer have been used for many years, but we lack high-quality evidence that one method is better than another (Heidenreich et al, 2011). The main options for localised prostate cancer are active surveillance, radical prostatectomy, and radiotherapy (RT) with or without adjuvant androgen deprivation therapy (ADT). For locally advanced prostate cancer, the treatment is mainly RT with hormone therapy (Heidenreich et al, 2011; Mottet et al, 2011). Many factors, including medical factors, patient preference, and resource availability, decide the choice of treatment (Cooperberg et al, 2010; Bosco et al, 2012; Kollmeier and Zelefsky, 2012).

With the development of technology and knowledge of radiation oncology, such as $3 \mathrm{D}$ conformal $\mathrm{RT}$ (3D-CRT) and intensity-modulated RT (IMRT) with their high dose and high precision, hundreds of clinical trials have been conducted to compare RT regimens with or without ADT for localised prostate 
cancer, with the aim to determine the optimal treatment with a balance of efficacy and tolerability.

With the development of evidence-based medicine, metaanalysis has become a dependable way to clarify clinical concerns or controversy. However, traditional head-to-head meta-analysis cannot reveal the relative effect of different treatment methods for localised prostate cancer. Randomised control trials (RCTs) usually contain two or a few arms, and trials cannot compare all possible treatment regimens. Fortunately, network meta-analysis can simultaneously combine both direct and indirect evidence from studies addressing the same clinical question to assess the relative efficacy of each treatment, while respecting randomisation (Lumley, 2002; Lu and Ades, 2006; Salanti et al, 2008).

In this study, we used network meta-analysis to identify the optimal radiation method for prostate cancer, comparing the relative efficacy and safety of different $\mathrm{RT}$ regimens. We evaluated hypofractionated RT (HFRT) and high- and low-dose RT (HDRT and LDRT) with or without ADT (long- or short-term ADT (LADT and SADT)).

\section{MATERIALS AND METHODS}

Literature search. We performed a literature search of MEDLINE via PubMed to identify RCTs of RT for localised prostate cancer published through July 2013. We used the following MeSH terms and free text words: (1) RT, radiation, irradiation, brachytherapy, 'proton beam', and 'dose fractionation'; (2) localised, locally, localisation, local; and (3) 'prostatic neoplasms/RT'[Majr]. Then we used the sensitivity- and precision-maximising version (2008 revision) to filter trials according to the Cochrane Handbook for Systematic Reviews of Interventions (JPT and Green, 2011). In addition, we reviewed reference lists of retrieved reviews or metaanalyses to identify further studies.

Study selection. Studies had to be RCTs, blinded or not, of previously untreated adults with localised prostate cancer without metastasis. Each arm had to involve an RT regimen, regardless of dosage or technique. We included reports published in English and reporting at least one of the outcomes mentioned below.

Exclusion criteria were a study of the imaging technique or radiation technique; the outcomes of interest not reported or insufficiently reported, such as outcomes from the first report or a subset of patients; abstracts from scientific meetings; and main therapy regimens being, for example, brachytherapy, cryoablation, different targets, fast neutrons, pion therapy, or $\beta$-carotene therapy to decrease the rate of side effects.

Three investigators (ZZ, JZ, and YL) independently reviewed the titles and abstracts for potential articles, then read the full text, with decisions made by consensus or consultation with a fourth investigator (MC). If results of study were reported several times, we chose the latest publication.

Data extraction and quality assessments. Three investigators independently extracted the following data: first author, publication year, and study location; study period and institution, length of follow-up; and patient charactertics, number of outcomes of interest, and interventions. We assessed the risk of bias by using the Cochrane Collaboration risk of bias tool to assess random sequence generation, allocation concealment, blinding, incomplete outcome data, selective outcome reporting, and other potential biases (JPT and Green, 2011). We did not assess blinding because blinding was not practicable in these trials. Disagreements during extraction were discussed with a fourth author.

Outcomes of interest included overall mortality (OM; from any cause), prostate cancer-specific mortality (CSM), PSA failure (biochemical failure), genitourinary (GU), and gastrointestinal (GI) toxicity grade $\geqslant 2$ according to Radiation Therapy Oncology
Group morbidity scales/European Organization for Research and Treatment of Cancer scoring criteria (Cox et al, 1995), or the National Cancer Institute of Canada Clinical Trials Group Expanded Common Toxicity Criteria. Prostate-specific antigen failure was determined as proposed by the American Society for Radiation Oncology (ASTRO), with $\geqslant 3$ consecutive increases in PSA level (Cox and Kaplan, 1997) or the ASTRO Phoenix definition ( $\geqslant$ nadir $+2 \mathrm{ng} \mathrm{ml}^{-1}$ ) (Roach III et al, 2006).

Interventions. Hypofractionated RT was defined as dose per fraction $>2.0 \mathrm{~Gy}$ and conventional RT as dose per session 1.8-2.0 Gy. High-dose radiation therapy was defined as total dose $>74 \mathrm{~Gy}$ and LDRT as total dose $\leqslant 70 \mathrm{~Gy}$. High-dose radiation therapy and LDRT for localised prostate cancer could consist of photon or proton therapy combined with conventional and conformational techniques to deliver external-beam RT. Reports of RCTs that compared RT alone or with ADT (regardless of drug and dosage) for localised prostate cancer were included. Trials exploring SADT vs LADT, (regardless of absolute values) with RT for localised or locally advanced prostate cancer were included.

Statistical analysis. We grouped regimens such as LDRT, HDRT, LDRT + SADT, or + LADT, HDRT + SADT, HFRT, and HFRT + SADT. We chose a dichotomous outcome for OM instead of overall survival because hazard ratios and $P$-values were reported for a few trials but most reports described OM. The number of patients was calculated on an intention-to-treat basis: the analysis of efficacy data was based on the total number of randomly assigned participants, regardless of how the investigators of the original study analysed the data. We used a conservative approach and imputed outcomes for the missing participants, assuming that they did not respond to treatment (Cipriani et al, 2009). For outcomes, if only percentages were reported, the actual number of events were estimated and rounded to the nearest whole number.

We performed a pair-wise meta-analysis by synthesising results of studies that compared the same interventions with a randomeffect model to incorporate the assumption that different studies assessed different yet related treatment effects (DerSimonian and Laird, 1986; Borenstein et al, 2011). We calculated odds ratios (ORs) and 95\% confidence intervals (95\% CIs). Heterogeneity was evaluated by the inconsistency statistics $\left(I^{2}\right)$, with values $<25 \%$ considered low heterogeneity and $>50 \%$ high heterogeneity (Higgins et al, 2003).

We used Bayesian network meta-analysis to incorporate both direct and indirect treatment comparisons for estimating the treatment effect between all interventions and ranked treatments in order (Lu and Ades, 2004). We compared outcome variables with a random-effect model. Each analysis was based on non-informative priors for effect sizes and precision. The estimates were obtained by the Markow Chain Monte Carlo method with 10000 initial iterations to burn in and the next 30000 iterations for estimations. The posterior mean of the residual deviance and deviance information criteria were used to evaluate the goodness of fit of the model. A model has good fit when residual deviance approximates the number of data points (Spiegelhalter et al, 2002). Conventionally, the results are presented by summarising the posterior distribution of the parameters of interest with means and $95 \%$ credible intervals. We also assessed the probability that each RT regimen was best in terms of efficacy, second best, third best, and so on, by calculating the OR for each regimen compared with control group. We ranked treatment regimens in terms of safety with the same methods. The LDRT group was considered the control group.

One key assumption of the network meta-analysis is the consistency between direct and indirect evidence, that is, whether the information of both sources of evidence are similar enough to be combined (Caldwell et al, 2010; Dias et al, 2011). 
This assumption was checked by the Bucher method (Bucher et al, 1997). Moreover, we calculated the difference between direct and indirect evidence in all closed loops in the network; inconsistent loops were identified with a significant $(95 \%$ credible interval that excludes 0) disagreement between direct and indirect evidence (Salanti et al, 2009).

We performed a sensitivity analysis by repeating the main computations using a fixed-effect model and a subgroup analysis by population (locally advanced or localised).

The results shown are from random-effect models with homogeneous between-trial variability. STATA 12.0 (Statacorp, College Station, TX, USA) was used for pair-wise meta-analysis, then R software (http://www.R-project.org, the R Foundation for Statistical Computing, Vienna, Austria) and WinBUGS 1.4.3 (MRC Biostatistics Unit, Cambridge, UK) for network meta-analysis.

Role of the funding source. There was no funding source for this study. The corresponding author had full access to all the data in the study and had final responsibility for the decision to submit for publication.

\section{RESULTS}

Characteristics of included trials. The electronic search yielded 1442 records, and after screening titles and abstracts, 204 records remained. We added another 18 articles from reviews, for 222 full-text articles assessed for eligibility. Finally, after excluding 161 articles, 61 reports assessing results of 27 RCTs (Zagars et al, 1988; Pilepich et al, 1995; Shipley et al, 1995; Pollack et al, 1996; Bolla et al, 1997; Lawton et al, 1997; Pilepich et al, 1997; Granfors et al, 1998; Nguyen et al, 1998; Pollack et al, 2000; Storey et al, 2000; Lawton et al, 2001; Pilepich et al, 2001; Bolla et al, 2002; Pollack et al, 2002; Hanks et al, 2003; Lamb et al, 2003; Yeoh et al, 2003; Ataman et al, 2004; Beckendorf et al, 2004; Crook et al, 2004; D'Amico et al, 2004; Laverdiere et al, 2004; Christie et al, 2005; Dearnaley et al, 2005; Denham et al, 2005; Lawton et al, 2005; Lukka et al, 2005; Peeters et al, 2005; Pilepich et al, 2005; Sathya et al, 2005; Zietman et al, 2005; Granfors et al, 2006; Peeters et al, 2006; Yeoh et al, 2006; Dearnaley et al, 2007; Al-Mamgani et al, 2008; D'Amico et al, 2008; Horwitz et al, 2008; Kuban et al, 2008; Roach et al, 2008; Bolla et al, 2009; Crook et al, 2009; Marzi et al, 2009; Strigari et al, 2009; Norkus et al, 2009a, 2009b; Alexander et al, 2010; Arcangeli et al, 2010; Bolla et al, 2010; Heemsbergen et al, 2010; Zietman et al, 2010; Al-Mamgani et al, 2011; Arcangeli et al, 2011; Armstrong et al, 2011; Beckendorf et al, 2011; Denham et al, 2011; Jones et al, 2011; Yeoh et al, 2011; Arcangeli et al, 2012; Dearnaley et al, 2012) were used in the network meta-analysis, for 13364 patients with local or locally advanced prostate cancer randomly assigned to receive one of the seven RT regimens examined (Figures 1 and 2). The median age of patients ranged from 65 to 75 years and median follow-up ranged from 1 to 14.5 years, mostly were from 5 to 10 years.

Morbidity of adverse events was not reported consistently, and some reports described GI or GU toxicity as grade 1 to 4 and others as $\geqslant 2$ or $\geqslant 3$ grade. We calculated the number of adverse events for the $\geqslant 2$ grade GI or GU toxicity. The number of outcome events included in the analysis was as follows: $3795 \mathrm{OM}$, 4530 PSA failure, 1241 CMS, 3523 acute GI (AGI) events, 3,316 acute GU (AGU) events, 2387 late GI (LGI) events, and 2276 late GU (LGU) events.

Many RT techniques were used, such as IMRT, 3D-CRT, and conventional RT, and the radiation dose ranged from the lowest, $55 \mathrm{~Gy}$ to the highest, $80 \mathrm{~Gy}$. Most trials used conventional fractionation, and some trials compared hypofractionation $\left(2.7-4.5 \mathrm{Gyf}^{-1}\right)$ to conventional fractionation (1.8 or $\left.2 \mathrm{Gyf}^{-1}\right)$.

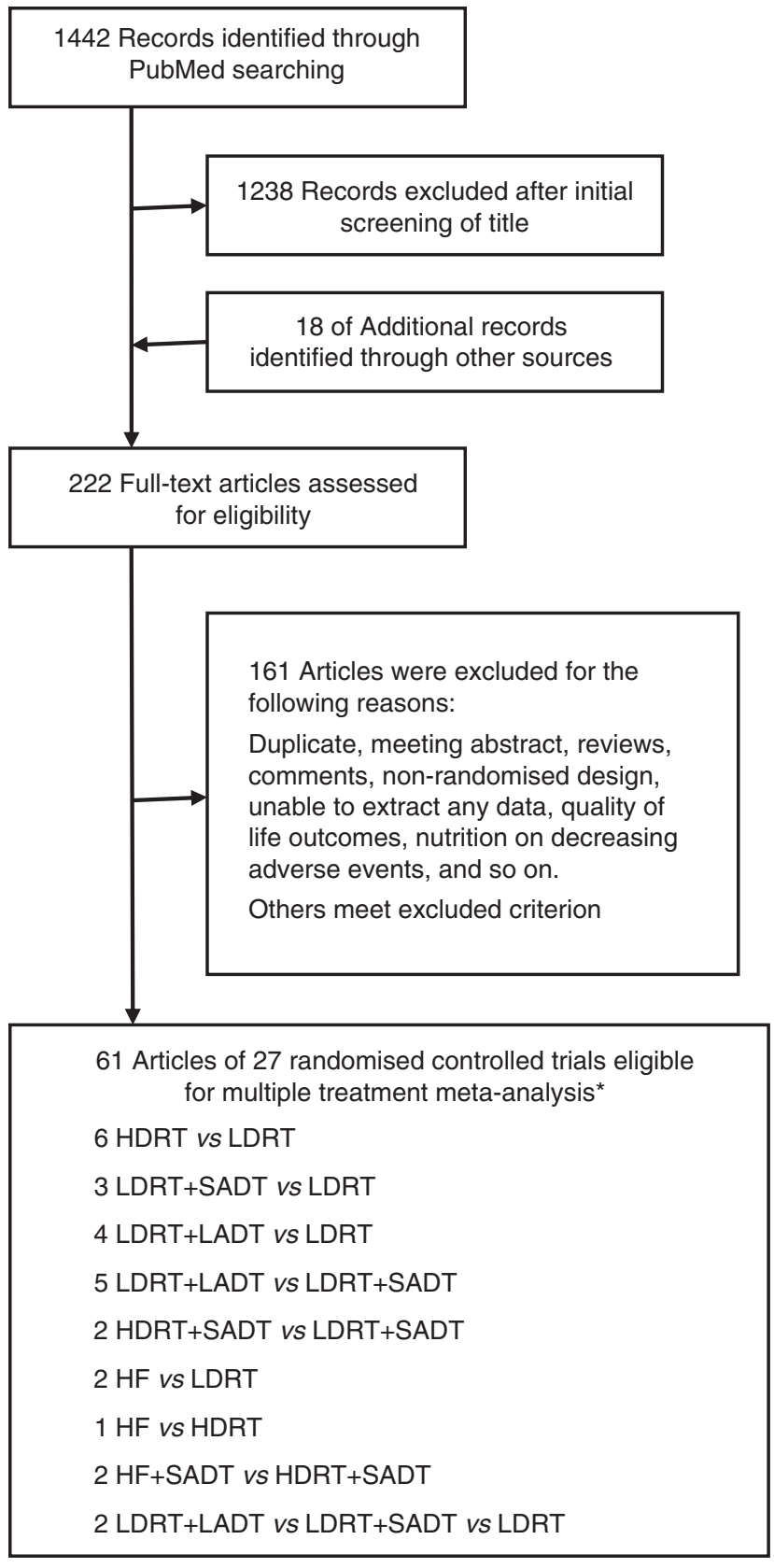

Figure 1. Study selection process. ${ }^{\star \star \prime}$ Indicates 27 randomised trials that correspond to 56 groups because two three-arm studies were included in this network meta-analysis.

Patients with RT plus ADT experienced different ADT durations. Most began at 3 to 6 months before RT to the end of RT, so SADT duration was $<10$ months, whereas LADT duration was $2-3$ years or the whole life (orchiectomy). The main characteristics of the included studies are in Supplementary Table 1.

The overall methodological quality was moderate (Supplementary Table 2). All included studies were RCTs, but most studies did not report the techniques for randomisation and concealment. When the article reported concealment carried out by a central office, we judged this as no bias.

Comparison of efficacy and safety. We directly compared efficacy and safety outcomes (Table 1 and Supplementary Table 3), showing that PSA control was associated with HDRT rather than LDRT, LDRT + SADT than LDRT, LDRT + LADT than LDRT + SADT, and HDRT + SADT than LDRT + SADT. 
For OM and CSM, LDRT + SADT and LDRT + LADT were better than LDRT alone. In addition, LDRT + LADT was better than LDRT + SADT for CSM. Hypofractionated RT produced more AGU events than LDRT but less than HDRT. High-dose radiation therapy was associated with increased risk of LGI and LGU events as compared with LDRT, and LDRT + SADT was associated with increased risk of LGU events as compared with LDRT + SADT. Overall, heterogeneity was high for most safety outcomes and moderate for efficacy outcomes. With direct comparisons, $I^{2}$ values were $>75 \%$ for the comparisons LDRT + LADT and LDRT + SADT for PSA failure and AGU events.

Network meta-analysis findings. The network meta-analysis results were based on a random-effects model (Table 2 and Supplementary Table 4) because they generally showed better goodness of fit and more conservative estimates than fixed-effect models (Supplementary Table 5).

The risk of OM was lower with LDRT + LADT and LDRT + SADT as compared with LDRT (ORs $0.64(0.53-0.77)$ and 0.75 (0.61-0.88)) and LDRT + LADT as compared with HDRT (OR $0.72(0.53-0.97))$. For PSA failure, apart from HFRT, all treatments

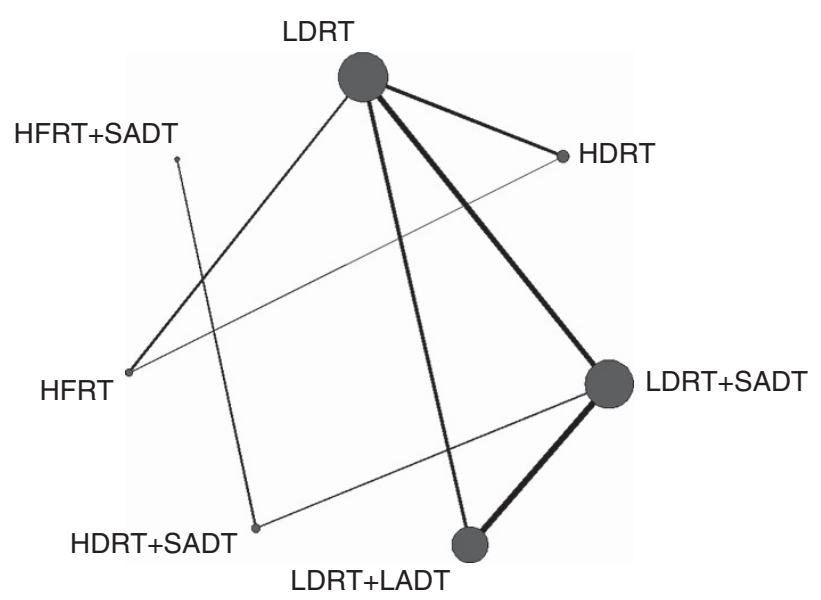

Figure 2. Network of eligible comparisons for the network meta-analysis for efficacy. The width of the lines is proportional to the number of trials comparing each pair of treatments, and the size of each node is proportional to the number of randomised participants (sample size). were associated with decreased risk as compared with LDRT. Moreover, HFRT + SADT was associated with decreased risk of PSA failure as compared with HFRT, LDRT + SADT, HDRT and LDRT, and LDRT + LADT as compared with LDRT + SADT, HDRT, and LDRT. However, HFRT alone was associated with increased risk of PSA failure as compared with HDRT + SADT, LDRT + LADT, and LDRT + SADT (ORs 2.98 (1.33-5.84), 2.46 (1.42-4.01), and 1.72 (1.01-2.92), respectively). Hypofractionated $\mathrm{RT}+\mathrm{SADT}$ was associated with decreased risk of CSM as compared with HFRT, LDRT + SADT, HDRT and LDRT (ORs 0.24 (0.02-0.96), 0.23 (0.02-0.85), 0.17 (0.01-0.62), and 0.14 (0.01-0.50), respectively). High-dose radiation therapy + SADT, LDRT + LADT, and LDRT + SADT were associated with decreased risk of CSM as compared with LDRT (ORs 0.43 (0.19-0.85), $0.48(0.35-0.63)$, and $0.6(0.42-0.78)$, respectively) as was LDRT + LADT compared with HDRT (OR 0.56 (0.32-0.93)). We found no significant associations for AGI and AGU or for LGU and LGI events in the random-effects models, except for HDRT associated with increased risk of LGI events as compared with LDRT (OR 1.85 (1.35-2.53)).

We also ranked treatments and estimated the cumulative probabilities of being the best treatment using random-effect models under the Bayesian framework (Supplementary Table 6). Furthermore, we estimated an inconsistency factor for each closed loops as the difference between direct and indirect estimates and the corresponding 95\% CI. Inconsistent loops are inconsistency factors with $95 \%$ CIs incompatible with zero. We found no inconsistent loops per network (Supplementary Table 7).

We performed a sensitive analysis using fixed-effect models (Supplementary Tables 8 and 9). However, random and fixedeffects models produced different results. More than $50 \%$ of patients were at the T3 or T4 tumor node metastasis stage in both trial arms, considered mainly locally advanced prostate cancer; similarly, trials of mainly $\mathrm{T} 1$ or $\mathrm{T} 2$ stage patients were considered as early-stage (localised prostate cancer) trials. We performed the subgroup analysis by early or locally advanced stage (Supplementary Tables 10,11, and 12). All seven RT treatments were used in early-stage trials, and only four treatments (LDRT, HDRT, LDRT + SADT, and LDRT + LADT) in locally advancedstage trials. In early-stage trials, OM and CSM did not differ by treatment method. Hypofractionated RT was associated with increased risk of PSA failure as compared with all other treatments except LDRT. In late-stage trials, LDRT + LADT was associated with decreased risk of OM, CSM, and PSA failure as compared with other treatments.

Table 1. Efficacy in meta-analysis of direct comparisons

\begin{tabular}{|c|c|c|c|c|c|c|c|c|c|c|c|c|}
\hline & \multicolumn{4}{|c|}{ OM } & \multicolumn{4}{|c|}{$\mathrm{BF}$} & \multicolumn{4}{|c|}{ CSM } \\
\hline & OR & $95 \% \mathrm{Cl}$ & $P$ & $1^{2}$ & OR & $95 \% \mathrm{Cl}$ & $\mathbf{P}$ & $1^{2}$ & OR & $95 \% \mathrm{Cl}$ & $\mathbf{P}$ & $1^{2}$ \\
\hline $\begin{array}{l}\text { HDRT vs LDRT } \\
\text { LDRT + SADT }\end{array}$ & $\begin{array}{l}0.91 \\
0.77\end{array}$ & $\begin{array}{l}0.72-1.14 \\
0.66-0.90\end{array}$ & $\begin{array}{l}0.395 \\
0.001\end{array}$ & $\begin{array}{l}0 \\
0\end{array}$ & $\begin{array}{l}0.61 \\
0.48\end{array}$ & $\begin{array}{l}0.49-0.76 \\
0.41-0.57\end{array}$ & $\begin{array}{l}0.000 \\
0.000\end{array}$ & $\begin{array}{l}0 \\
0\end{array}$ & $\begin{array}{l}0.92 \\
0.51\end{array}$ & $\begin{array}{l}0.67-1.26 \\
0.38-0.67\end{array}$ & $\begin{array}{l}0.586 \\
0.000\end{array}$ & $\begin{array}{l}0 \\
0\end{array}$ \\
\hline LDRT + LADT & 0.65 & $0.48-0.87$ & 0.004 & $28.20 \%$ & - & - & - & - & 0.56 & $0.38-0.83$ & 0.004 & $44.20 \%$ \\
\hline LDRT + LADT & 0.86 & $0.71-1.06$ & 0.160 & $30.90 \%$ & 0.65 & $0.44-0.96$ & 0.030 & $82.60 \%$ & 0.71 & $0.53-0.95$ & 0.023 & $21.60 \%$ \\
\hline HDRT + SADT & 1.1 & $0.72-1.69$ & 0.671 & & 0.64 & $0.48-0.83$ & 0.001 & 0 & 0.62 & $0.21-1.81$ & 0.383 & $43.80 \%$ \\
\hline $\begin{array}{l}\text { HFRT vs LDRT } \\
\text { HFRT vs HDRT } \\
\text { HFRT + SADT } \\
\text { vs HDRT + SADT }\end{array}$ & $\begin{array}{l}0.86 \\
0.94 \\
0.43\end{array}$ & $\begin{array}{l}0.62-1.20 \\
0.06-15.42 \\
0.17-1.12\end{array}$ & $\begin{array}{l}0.380 \\
0.962 \\
0.083\end{array}$ & 0 & $\begin{array}{l}0.84 \\
0.61 \\
0.63\end{array}$ & $\begin{array}{l}0.67-1.07 \\
0.10-3.82 \\
0.28-1.40\end{array}$ & $\begin{array}{l}0.151 \\
0.595 \\
0.258\end{array}$ & 0 & $\begin{array}{l}0.67 \\
0.28\end{array}$ & $\begin{array}{c}0.34-1.34 \\
- \\
0.06-1.37\end{array}$ & $\begin{array}{c}0.257 \\
- \\
0.144\end{array}$ & $\begin{array}{l}0 \\
-\end{array}$ \\
\hline
\end{tabular}




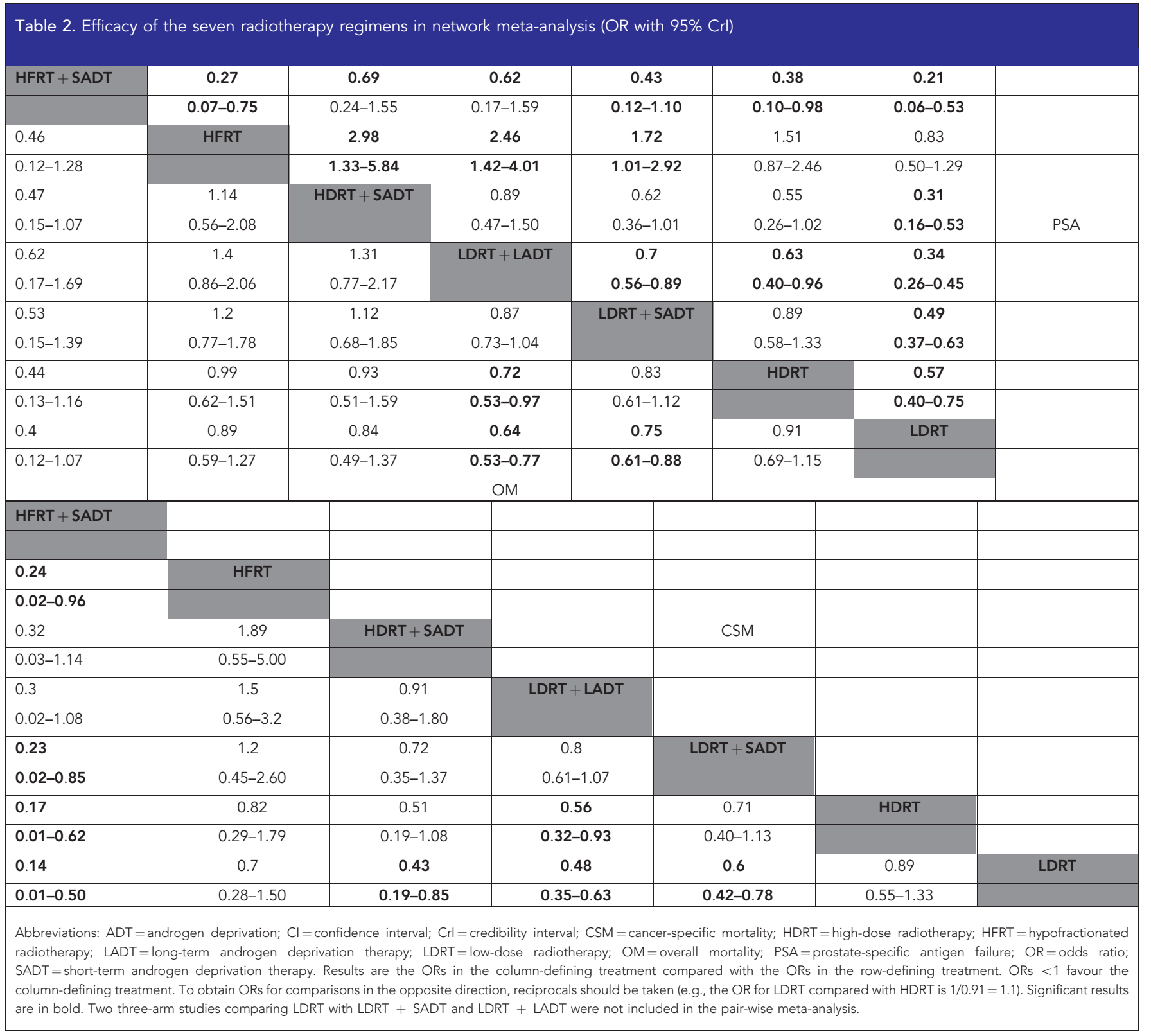

\section{DISCUSSION}

Our network meta-analysis was based on 27 RCTs of 13364 patients who underwent seven RT regimens for prostate cancer. We aimed to synthesise data on RT for prostate cancer to help in choosing a regimen that balances efficacy and safety for treating localised or locally advanced prostate cancer. Low-dose radiation therapy plus ADT might be associated with reduced risk of OM as compared with RT alone. Except for HDRT and HFRT, all RT regimens were associated with decreased risk of CSM as compared with LDRT. In addition, except HFRT as compared with LDRT, all regimens were associated with reduced risk of PSA failure. Hypofractionated RT plus SADT might be the most efficacious for local prostate cancer.

We found no difference among the seven RT regimens in toxicity. However, HDRT or LDRT plus ADT might be associated with reduced risk of acute toxicity as compared with RT alone. Only HDRT alone was associated with increased risk of LGI events as compared with LDRT alone. Low-dose radiation therapy alone might have the lowest late-toxicity rate. The most efficacious treatment (HFRT plus ADT) might not be the best for overall acceptability because of some toxicity.

Hypofractionated RT plus ADT was the most efficient for localised prostate cancer, especially in terms of reduced risk of PSA failure as compared with RT alone, but with the worst toxicity. Hypofractionated RT without ADT was associated with increased risk of OM, CSM, and PSA failure as compared with other treatments except RT alone (low or high dose), as with toxicity outcomes. Our findings may not agree with hypothesis of fewer but larger-than-conventional fractions being equal to high doses with conventional fraction sizes for efficacy with reduced total dose. Patients who received HFRT showed the reverse outcomes with or without short ADT. Notably, HFRT might be associated, but not significantly, with reduced risk of LGU events as compared with other treatments except LDRT alone. An important randomised trial had been published in 2013 comparing conventional fraction RT (2.0 $\mathrm{Gyf}^{-1}$ ) with HFRT (2.7Gyf ${ }^{-1}$ ) (Pollack et al, 2013). We could not group the arms in this trial for half of the patients in both arms received short or long ADT. In this trial, the hypofractionation regimen did not result in a significant reduction in biochemical and/or clinical disease failure, and this is consistent 
with our pair-wise meta-analysis. In a traditional meta-analysis comparing HFRT with conventional fractionated RT, HFRT was associated with AGI toxicity, especially as compared with HDRT, and HFRT for localised prostate cancer was not superior to conventional therapy (Botrel et al, 2013). To some extent, these data are consistent with our network meta-analysis results. However, in our pair-wise meta-analysis, HFRT was associated with reduced risk of AGU events as compared with HDRT and increased risk of AGU events as compared with LDRT. We classified seven groups for only one trial included in each traditional meta-analysis and excluded the trials in the Botrel's meta-analysis because they did not meet inclusion criteria.

Hormone therapy has been used for decades as the sole treatment or as an adjuvant to RT for prostate cancer. In our network meta-analysis, overall, RT plus ADT significantly reduced the risk of OM, CSM, and PSA failure as compared with RT alone. Especially LDRT + LADT was associated with reduced risk of OM, CSM, and PSA failure as compared with HDRT or LDRT alone, and might be the second-best therapy for localised or locally advanced prostate cancer. In terms of toxicity, we observed no statistically significant differences among therapies, but the combination regimens might be associated with reduced risk of AGI events as compared with RT alone. In the Bria et al study (Bria et al, 2009), GU and GI events rates were reduced, but not significantly, with combination therapy, but acute or late toxicity was not described. In our pair-wise metaanalysis, LDRT with SADT or LADT had significant efficacy as compared with LDRT alone, which is similar to the Bria et al study (Bria et al, 2009).

Although our results confirmed the benefit of combination therapy for localised or locally advanced prostate cancer, the optimal duration of ADT added to RT remains is unknown. In our network meta-analysis and pair-wise meta-analysis, LDRT + LADT was associated with reduced risk of OM, CSM, and PSA failure as compared with LDRT + SADT. However, as compared with HDRT + SADT, LDRT + LADT was associated with increased risk of CSM and PSA failure. The Cuppone et al study (Cuppone et al, 2010) also favored LADT added to RT for locally advanced prostate cancer. Combined with LDRT, LADT might increase the risk of toxicity as compared with SADT. A spinodal effect might occur with increased duration of adjuvant ADT along with decreased toxicity, and then the spinodal point increases. However, we did not evaluate the optimal timing of ADT.

Our network meta-analysis indicated a trend in that HDRT gave the expect results and increased the early or late toxicity. While Michalski et al (Michalski et al, 2013) study showed that a trend for clinically reduction in late G2 + GI toxicity with HDRT using IMRT compared with 3D-CRT . And in another review (Bauman et al, 2012), the findings were in favour of IMRT over 3D-CRT in the radical treatment of localised prostate cancer when doses were $>70 \mathrm{~Gy}$. However, we excluded the trials comparing different RT technique using same doses, and in most of the trials in our study, the group of HDRT used the 3D-CRT, thereby increasing the toxicity. In pair-wise meta-analysis, HDRT significantly reduced the risk of PSA failure as compared with LDRT, which is consistent with the Viani et al (Viani et al, 2009).

In the subgroup analysis, the seven treatments were examined in early-stage trials with four treatments in advanced-stage trials. With the advent of PSA screening, stage migration has resulted in the diagnosis of many men with potentially clinically insignificant disease. This finding might explain why no new RT technique was tested for locally advanced prostate cancer.

Our methodological approach was innovative. First, the division of RT methods was more exact and useful than the classes used in pair-wise meta-analysis. Second, to our knowledge, this is the first comparison of direct, indirect, and network approaches. This approach allowed us to incorporate all available evidence to estimate treatments more precisely. Third, for comparing trials with similar clinical features, we excluded trials of branch RT for high dose (>100 Gy) or ADT alone and included patients with localised or locally advanced prostate cancer.

A possible limitation of the analysis is that we used published data rather than individual patient information. Individual patient data might produce a more detailed appraisal of outcomes for different risk groups. Even with the use of individual patient information in such a complex network of multiple treatments, the power to detect effect modifications might still be limited (Trikalinos and Ioannidis, 2001; Mauri et al, 2008). Adequate information about randomisation and allocation concealment was not reported in many included trials that might undermine the validity of overall findings (Cipriani et al, 2009). In addition, in a retrospective meta-analysis, selective reporting bias and publication bias cannot be avoided. Finally, in subgroup analysis, we classified the trials subjectively as early- or late-stage, and the results by different follow-up duration. Therefore, our results might over- or underestimate findings and strong inferences should be avoided.

In conclusion, HFRT + SADT might be the most efficacious treatment but with worst toxicity for localised or locally advanced prostate cancer, and HDRT may represent good efficacy but more adverse events. Considering the small number of patients in our HFRT groups and not long enough follow-up duration, more trials with large number of patients should be implemented to evaluate this method. However, with the advent of PSA screening, more patients are showing early-stage cancer, with long-life expectancy, so decreasing adverse events should be a concern with new RT (such as IMRT or Image Guided RT) techniques or regimens.

\section{AUTHOR CONTRIBUTIONS}

$\mathrm{KL}$ and $\mathrm{ZZ}$ were responsible for the study concept and design. ZZ, JZ, YL and MC acquired data, which were analysed and interpreted by $\mathrm{ZZ}$ and $\mathrm{JZ} \mathrm{ZZ}$ drafted the report. ZZ and PG performed the statistical analysis.

\section{CONFLICT OF INTEREST}

The authors declare no conflict of interest.

\section{REFERENCES}

Al-Mamgani A, van Putten WL, Heemsbergen WD, van Leenders GJ, Slot A, Dielwart MF, Incrocci L, Lebesque JV (2008) Update of Dutch multicenter dose-escalation trial of radiotherapy for localized prostate cancer. Int J Radiat Oncol Biol Phys 72(4): 980-988.

Al-Mamgani A, van Putten WL, van der Wielen GJ, Levendag PC, Incrocci L (2011) Dose escalation and quality of life in patients with localized prostate cancer treated with radiotherapy: long-term results of the Dutch randomized dose-escalation trial (CKTO 96-10 trial). Int J Radiat Oncol Biol Phys 79(4): 1004-1012.

Alexander A, Crook J, Jones S, Malone S, Bowen J, Truong P, Pai H, Ludgate C (2010) Is biochemical response more important than duration of neoadjuvant hormone therapy before radiotherapy for clinically localized prostate cancer? An analysis of the 3-versus 8-month randomized trial. Int J Radiat Oncol Biol Phys 76(1): 23-30.

Arcangeli G, Fowler J, Gomellini S, Arcangeli S, Saracino B, Petrongari MG, Benassi M, Strigari L (2011) Acute and late toxicity in a randomized trial of conventional versus hypofractionated three-dimensional conformal radiotherapy for prostate cancer. Int J Radiat Oncol Biol Phys 79(4): 1013-1021.

Arcangeli G, Saracino B, Gomellini S, Petrongari MG, Arcangeli S, Sentinelli S, Marzi S, Landoni V, Fowler J, Strigari L (2010) A prospective phase III randomized trial of hypofractionation versus conventional fractionation in 
patients with high-risk prostate cancer. Int J Radiat Oncol Biol Phys 78(1): $11-18$.

Arcangeli S, Strigari L, Gomellini S, Saracino B, Petrongari MG, Pinnarò P, Pinzi V, Arcangeli G (2012) Updated results and patterns of failure in a randomized hypofractionation trial for high-risk prostate cancer. Int $J$ Radiat Oncol Biol Phys 84(5): 1172-1178.

Armstrong JG, Gillham CM, Dunne MT, Fitzpatrick DA, Finn MA, Cannon ME, Taylor JC, O'Shea CM, Buckney SJ, Thirion PG (2011) A randomized trial (Irish clinical oncology research group 97-01) comparing short versus protracted neoadjuvant hormonal therapy before radiotherapy for localized prostate cancer. Int J Radiat Oncol Biol Phys 81(1): 35-45.

Ataman F, Zurlo A, Artignan X, van Tienhoven G, Blank LE, Warde P, Dubois JB, Jeanneret W, Keuppens F, Bernier J (2004) Late toxicity following conventional radiotherapy for prostate cancer: analysis of the EORTC trial 22863. Eur J Cancer 40(11): 1674-1681.

Bauman G, Rumble R, Chen J, Loblaw A, Warde P (2012) Intensitymodulated radiotherapy in the treatment of prostate cancer. Clin Oncol 24(7): 461-473.

Beckendorf V, Guerif S, Le Prisé E, Cosset J-M, Bougnoux A, Chauvet B, Salem N, Chapet O, Bourdain S, Bachaud J-M (2011) 70 Gy versus 80 Gy in localized prostate cancer: 5-year results of GETUG 06 randomized trial. Int J Radiat Oncol Biol Phys 80(4): 1056-1063.

Beckendorf V, Guérif S, Le Prisé E, Cosset JM, Lefloch O, Chauvet B, Salem N, Chapet O, Bourdin S, Bachaud JM (2004) The GETUG 70 Gy vs 80 Gy randomized trial for localized prostate cancer: feasibility and acute toxicity. Int J Radiat Oncol Biol Phys 60(4): 1056-1065.

Bolla M, Collette L, Blank L, Warde P, Dubois JB, Mirimanoff R-O, Storme G, Bernier J, Kuten A, Sternberg C (2002) Long-term results with immediate androgen suppression and external irradiation in patients with locally advanced prostate cancer (an EORTC study): a phase III randomised trial. Lancet 360(9327): 103-108.

Bolla M, De Reijke TM, Van Tienhoven G, Van den Bergh AC, Oddens J, Poortmans PM, Gez E, Kil P, Akdas A, Soete G (2009) Duration of androgen suppression in the treatment of prostate cancer. New Engl J Med 360(24): 2516-2527.

Bolla M, Gonzalez D, Warde P, Dubois JB, Mirimanoff R-O, Storme G, Bernier J, Kuten A, Sternberg C, Gil T (1997) Improved survival in patients with locally advanced prostate cancer treated with radiotherapy and goserelin. New Engl J Med 337(5): 295-300.

Bolla M, Van Tienhoven G, Warde P, Dubois JB, Mirimanoff R-O, Storme G, Bernier J, Kuten A, Sternberg C, Billiet I (2010) External irradiation with or without long-term androgen suppression for prostate cancer with high metastatic risk: 10-year results of an EORTC randomised study. Lancet Oncol 11(11): 1066-1073.

Borenstein M, Hedges LV, Higgins JP, Rothstein HR (2011) Introduction to Meta-analysis. Wiley.com.

Bosco JL, Halpenny B, Berry DL (2012) Personal preferences and discordant prostate cancer treatment choice in an intervention trial of men newly diagnosed with localized prostate cancer. Health Qual Life Outcomes 10(1): 123.

Botrel TE, Clark O, Pompeo AC, Bretas FF, Sadi MV, Ferreira U, Dos Reis RB (2013) Hypofractionated external-beam radiation therapy (HEBRT) versus conventional external-beam radiation (CEBRT) in patients with localized prostate cancer: a systematic review and meta-analysis. Core Evidence 8: 1-13.

Bria E, Cuppone F, Giannarelli D, Milella M, Ruggeri EM, Sperduti I, Pinnarò P, Terzoli E, Cognetti F, Carlini P (2009) Does hormone treatment added to radiotherapy improve outcome in locally advanced prostate cancer? Cancer 115(15): 3446-3456.

Bucher HC, Guyatt GH, Griffith LE, Walter SD (1997) The results of direct and indirect treatment comparisons in meta-analysis of randomized controlled trials. J Clin Epidemiol 50(6): 683-691.

Caldwell DM, Welton NJ, Ades A (2010) Mixed treatment comparison analysis provides internally coherent treatment effect estimates based on overviews of reviews and can reveal inconsistency. J Clin Epidemiol 63(8): 875-882.

Christie D, Denham J, Steigler A, Lamb D, Turner S, Mameghan H, Joseph D, Matthews J, Franklin I, Atkinson C (2005) Delayed rectal and urinary symptomatology in patients treated for prostate cancer by radiotherapy with or without short term neo-adjuvant androgen deprivation. Radiother Oncol 77(2): 117-125.
Cipriani A, Furukawa TA, Salanti G, Geddes JR, Higgins J, Churchill R, Watanabe N, Nakagawa A, Omori IM, McGuire H (2009) Comparative efficacy and acceptability of 12 new-generation antidepressants: a multiple-treatments meta-analysis. Lancet 373(9665): 746-758.

Cooperberg MR, Broering JM, Carroll PR (2010) Time trends and local variation in primary treatment of localized prostate cancer. J Clin Oncol 28(7): 1117-1123.

Cox J, Kaplan G. American Society for Therapeutic Radiology and Oncology Consensus Panel (1997) Consensus statement: guidelines for PSA following radiation therapy. Int J Radiat Oncol Biol Phys 37: 1035-1041.

Cox JD, Stetz J, Pajak TF (1995) Toxicity criteria of the radiation therapy oncology group (RTOG) and the European organization for research and treatment of cancer (EORTC). Int J Radiat Oncol Biol Phys 31(5): 1341-1346.

Crook J, Ludgate C, Malone S, Lim J, Perry G, Eapen L, Bowen J, Robertson S, Lockwood G (2004) Report of a multicenter Canadian phase III randomized trial of 3 months vs 8 months neoadjuvant androgen deprivation before standard-dose radiotherapy for clinically localized prostate cancer. Int J Radiat Oncol Biol Phys 60(1): 15-23.

Crook J, Ludgate C, Malone S, Perry G, Eapen L, Bowen J, Robertson S, Lockwood G (2009) Final report of multicenter Canadian Phase III randomized trial of 3 versus 8 months of neoadjuvant androgen deprivation therapy before conventional-dose radiotherapy for clinically localized prostate cancer. Int J Radiat Oncol Biol Phys 73(2): 327-333.

Cuppone F, Bria E, Giannarelli D, Vaccaro V, Milella M, Nisticò C, Ruggeri E, Sperduti I, Bracarda S, Pinnarò P (2010) Impact of hormonal treatment duration in combination with radiotherapy for locally advanced prostate cancer: meta-analysis of randomized trials. BMC Cancer 10(1): 675 .

D’Amico AV, Manola J, Loffredo M, Renshaw AA, DellaCroce A, Kantoff PW (2004) 6-month androgen suppression plus radiation therapy $v s$ radiation therapy alone for patients with clinically localized prostate cancer. JAMA 292(7): 821-827.

Dearnaley D, Hall E, Lawrence D, Huddart R, Eeles R, Nutting C, Gadd J, Warrington A, Bidmead M, Horwich A (2005) Phase III pilot study of dose escalation using conformal radiotherapy in prostate cancer: PSA control and side effects. Br J Cancer 92(3): 488-498.

Dearnaley D, Syndikus I, Sumo G, Bidmead M, Bloomfield D, Clark C, Gao A, Hassan S, Horwich A, Huddart R (2012) Conventional versus hypofractionated high-dose intensity-modulated radiotherapy for prostate cancer: preliminary safety results from the $\mathrm{CHHiP}$ randomised controlled trial. Lancet Oncol 13(1): 43-54.

Dearnaley DP, Sydes MR, Graham JD, Aird EG, Bottomley D, Cowan RA, Huddart RA, Jose CC, Matthews JH, Millar J (2007) Escalated-dose versus standard-dose conformal radiotherapy in prostate cancer: first results from the MRC RT01 randomised controlled trial. Lancet Oncol 8(6): 475-487.

Denham JW, Steigler A, Lamb DS, Joseph D, Mameghan H, Turner S, Matthews J, Franklin I, Atkinson C, North J (2005) Short-term androgen deprivation and radiotherapy for locally advanced prostate cancer: results from the Trans-Tasman Radiation Oncology Group 96.01 randomised controlled trial. Lancet Oncol 6(11): 841-850.

Denham JW, Steigler A, Lamb DS, Joseph D, Turner S, Matthews J, Atkinson C, North J, Christie D, Spry NA (2011) Short-term neoadjuvant androgen deprivation and radiotherapy for locally advanced prostate cancer: 10-year data from the TROG 96.01 randomised trial. Lancet Oncol 12(5): 451-459.

DerSimonian R, Laird N (1986) Meta-analysis in clinical trials. Control Clin Trials 7(3): 177-188.

Dias S, Sutton AJ, Welton NJ, Ades A (2011) NICE DSU Technical Support Document 3: Heterogeneity: subgroups, meta-regression, bias and bias-adjustment: Forthcoming.

D’Amico AV, Chen M-H, Renshaw AA, Loffredo M, Kantoff PW (2008) Androgen suppression and radiation $v s$ radiation alone for prostate cancer. JAMA 299(3): 289-295.

Granfors T, Modig H, Damber J-E, Tomic R (1998) Combined orchiectomy and external radiotherapy versus radiotherapy alone for nonmetastatic prostate cancer with or without pelvic lymph node involvement: a prospective randomized study. J Urol 159(6): 2030-2034.

Granfors T, Modig H, Damber J-E, Tomic R (2006) Long-term followup of a randomized study of locally advanced prostate cancer treated with combined orchiectomy and external radiotherapy versus radiotherapy alone. J Urol 176(2): 544-547. 
Hanks GE, Pajak TF, Porter A, Grignon D, Brereton H, Venkatesan V, Horwitz EM, Lawton C, Rosenthal SA, Sandler HM (2003) Phase III trial of long-term adjuvant androgen deprivation after neoadjuvant hormonal cytoreduction and radiotherapy in locally advanced carcinoma of the prostate: the Radiation Therapy Oncology Group Protocol 92-02. J Clin Oncol 21(21): 3972-3978.

Heemsbergen WD, Al-Mamgani A, Witte MG, Van Herk M, Pos FJ, Lebesque JV (2010) Urinary obstruction in prostate cancer patients from the dutch trial ( 68 gy $v s 78$ gy): Relationships with local dose, acute effects, and baseline characteristics. Int J Radiat Oncol Biol Phys 78(1): 19-25.

Heidenreich A, Bellmunt J, Bolla M, Joniau S, Mason M, Matveev V, Mottet N, Schmid H-P, van der Kwast T, Wiegel T (2011) EAU guidelines on prostate cancer. Part 1: screening, diagnosis, and treatment of clinically localised disease. Eur Urol 59(1): 61-71.

Higgins JP, Thompson SG, Deeks JJ, Altman DG (2003) Measuring inconsistency in meta-analyses. BMJ 327(7414): 557.

Horwitz EM, Bae K, Hanks GE, Porter A, Grignon DJ, Brereton HD, Venkatesan V, Lawton CA, Rosenthal SA, Sandler HM (2008) Ten-year follow-up of radiation therapy oncology group protocol 92-02: a phase III trial of the duration of elective androgen deprivation in locally advanced prostate cancer. J Clin Oncol 26(15): 2497-2504.

Jemal A, Bray F, Center MM, Ferlay J, Ward E, Forman D (2011) Global cancer statistics. CA Cancer J Clin 61(2): 69-90.

Jemal A, Siegel R, Ward E, Murray T, Xu J, Smigal C, Thun MJ (2006) Cancer statistics, 2006. CA Cancer J Clin 56(2): 106-130.

Jones CU, Hunt D, McGowan DG, Amin MB, Chetner MP, Bruner DW, Leibenhaut MH, Husain SM, Rotman M, Souhami L (2011) Radiotherapy and short-term androgen deprivation for localized prostate cancer. New Engl J Med 365(2): 107-118.

PTH Julian, Green S (2011) Cochrane handbook for systematic reviews of interventions version 5.1. 0 [updated March 2011]. The Cochrane Collaboration.

Kollmeier MA, Zelefsky MJ (2012) How to select the optimal therapy for early-stage prostate cancer. Crit Rev Oncol/Hematol 84: e6-e15.

Kuban DA, Tucker SL, Dong L, Starkschall G, Huang EH, Cheung MR, Lee AK, Pollack A (2008) Long-term results of the MD Anderson randomized dose-escalation trial for prostate cancer. Int $J$ Radiat Oncol Biol Phys 70(1): 67-74.

Lamb DS, Denham JW, Mameghan H, Joseph D, Turner S, Matthews J, Franklin I, Atkinson C, North J, Poulsen M (2003) Acceptability of short term neo-adjuvant androgen deprivation in patients with locally advanced prostate cancer. Radiother Oncol 68(3): 255-267.

Laverdiere J, Nabid A, De Bedoya LD, Ebacher A, Fortin A, Wang CS, Harel F (2004) The efficacy and sequencing of a short course of androgen suppression on freedom from biochemical failure when administered with radiation therapy for T2-T3 prostate cancer. J Urol 171(3): 1137-1140.

Lawton CA, Winter K, Byhardt R, Sause WT, Hanks GE, Russell AH, Rotman M, Porter A, McGowan DG, DelRowe JD (1997) Androgen suppression plus radiation versus radiation alone for patients with D1 $(\mathrm{pN}+)$ adenocarcinoma of the prostate (results based on a national prospective randomized trial, RTOG 85-31). Int J Radiat Oncol Biol Phys 38(5): 931-939.

Lawton CA, Winter K, Grignon D, Pilepich MV (2005) Androgen suppression plus radiation versus radiation alone for patients with stage D1/pathologic node-positive adenocarcinoma of the prostate: updated results based on national prospective randomized trial Radiation Therapy Oncology Group 85-31. J Clin Oncol 23(4): 800-807.

Lawton CA, Winter K, Murray K, Machtay M, Mesic JB, Hanks GE, Coughlin CT, Pilepich MV (2001) Updated results of the phase III Radiation Therapy Oncology Group (RTOG) trial 85-31 evaluating the potential benefit of androgen suppression following standard radiation therapy for unfavorable prognosis carcinoma of the prostate. Int $J$ Radiat Oncol Biol Phys 49(4): 937-946.

Lu G, Ades A (2004) Combination of direct and indirect evidence in mixed treatment comparisons. Statist Med 23(20): 3105-3124.

Lu G, Ades A (2006) Assessing evidence inconsistency in mixed treatment comparisons. J Am Statist Assoc 101: 447-459.

Lukka H, Hayter C, Julian JA, Warde P, Morris WJ, Gospodarowicz M, Levine M, Sathya J, Choo R, Prichard H (2005) Randomized trial comparing two fractionation schedules for patients with localized prostate cancer. J Clin Oncol 23(25): 6132-6138.
Lumley T (2002) Network meta-analysis for indirect treatment comparisons. Statist Med 21(16): 2313-2324.

Marzi S, Saracino B, Petrongari MG, Arcangeli S, Gomellini S, Arcangeli G, Benassi M, Landoni V (2009) Modeling of alpha/beta for late rectal toxicity from a randomized phase II study: conventional versus hypofractionated scheme for localized prostate cancer. J Exp Clin Cancer Res 28: 117.

Mauri D, Polyzos NP, Salanti G, Pavlidis N, Ioannidis JP (2008) Multiple-treatments meta-analysis of chemotherapy and targeted therapies in advanced breast cancer. J Natl Cancer Inst 100(24): 1780-1791.

Michalski JM, Yan Y, Watkins-Bruner D, Bosch WR, Winter K, Galvin JM, Bahary J-P, Morton GC, Parliament MB, Sandler HM (2013) Preliminary toxicity analysis of 3-dimensional conformal radiation therapy versus intensity modulated radiation therapy on the high-dose arm of the Radiation Therapy Oncology Group 0126 prostate cancer trial. Int J Radiat Oncol Biol Phys 87(5): 932-938.

Mottet N, Bellmunt J, Bolla M, Joniau S, Mason M, Matveev V, Schmid H-P, Van der Kwast T, Wiegel T, Zattoni F (2011) EAU guidelines on prostate cancer. Part II: Treatment of advanced, relapsing, and castration-resistant prostate cancer. Actas Urológicas Españolas 35(10): 565-579.

Nguyen LN, Pollack A, Zagars GK (1998) Late effects after radiotherapy for prostate cancer in a randomized dose-response study: results of a self-assessment questionnaire. Urology 51(6): 991-997.

Norkus D, Miller A, Kurtinaitis J, Haverkamp U, Popov S, Prott F-J, Valuckas KP (2009a) A randomized trial comparing hypofractionated and conventionally fractionated three-dimensional external-beam radiotherapy for localized prostate adenocarcinoma. Strahlentherapie Und Onkologie 185(11): 715-721.

Norkus D, Miller A, Plieskiene A, Janulionis E, Valuckas KP (2009b) A randomized trial comparing hypofractionated and conventionally fractionated three-dimensional conformal external-beam radiotherapy for localized prostate adenocarcinoma: a report on the first-year biochemical response. Medicina (Kaunas 45(6): 469-475.

Peeters ST, Heemsbergen WD, Koper PC, van Putten WL, Slot A, Dielwart MF, Bonfrer JM, Incrocci L, Lebesque JV (2006) Dose-response in radiotherapy for localized prostate cancer: results of the Dutch multicenter randomized phase III trial comparing 68 Gy of radiotherapy with 78 Gy. J Clin Oncol 24(13): 1990-1996.

Peeters ST, Heemsbergen WD, van Putten WL, Slot A, Tabak H, Mens JW, Lebesque JV, Koper P (2005) Acute and late complications after radiotherapy for prostate cancer: results of a multicenter randomized trial comparing 68 Gy to 78 Gy. Int J Radiat Oncol Biol Phys 61(4): 1019-1034.

Pilepich M, Caplan R, Byhardt R, Lawton C, Gallagher M, Mesic J, Hanks G, Coughlin C, Porter A, Shipley W (1997) Phase III trial of androgen suppression using goserelin in unfavorable-prognosis carcinoma of the prostate treated with definitive radiotherapy: report of Radiation Therapy Oncology Group Protocol 85-31. J Clin Oncol 15(3): 1013-1021.

Pilepich MV, Sause WT, Shipley WU, Krall JM, Lawton CA, Grignon D, Al-Sarraf M, Abrams RA, Caplan R, John MJ (1995) Androgen deprivation with radiation therapy compared with radiation therapy alone for locally advanced prostatic carcinoma: a randomized comparative trial of the Radiation Therapy Oncology Group. Urology 45(4): 616-623.

Pilepich MV, Winter K, John MJ, Mesic JB, Sause W, Rubin P, Lawton C, Machtay M, Grignon D (2001) Phase III radiation therapy oncology group (RTOG) trial 86-10 of androgen deprivation adjuvant to definitive radiotherapy in locally advanced carcinoma of the prostate. Int $J$ Radiat Oncol Biol Phys 50(5): 1243-1252.

Pilepich MV, Winter K, Lawton CA, Krisch RE, Wolkov HB, Movsas B, Hug EB, Asbell SO, Grignon D (2005) Androgen suppression adjuvant to definitive radiotherapy in prostate carcinoma-long-term results of phase III RTOG 85-31. Int J Radiat Oncol Biol Phys 61(5): 1285-1290.

Pollack A, Walker G, Horwitz EM, Price R, Feigenberg S, Konski AA, Stoyanova R, Movsas B, Greenberg RE, Uzzo RG (2013) Randomized trial of hypofractionated external-beam radiotherapy for prostate cancer. J Clin Oncol 31(31): 3860-3868.

Pollack A, Zagars GK, Smith LG, Lee JJ, von Eschenbach AC, Antolak JA, Starkschall G, Rosen I (2000) Preliminary results of a randomized radiotherapy dose-escalation study comparing 70 Gy with 78 Gy for prostate cancer. J Clin Oncol 18(23): 3904-3911.

Pollack A, Zagars GK, Starkschall G, Antolak JA, Lee JJ, Huang E, von Eschenbach AC, Kuban DA, Rosen I (2002) Prostate cancer radiation dose response: results of the MD Anderson phase III randomized trial. Int J Radiat Oncol Biol Phys 53(5): 1097-1105. 
Pollack A, Zagars GK, Starkschall G, Childress CH, Kopplin S, Boyer AL, Rosen II (1996) Conventional vs conformal radiotherapy for prostate cancer: preliminary results of dosimetry and acute toxicity. Int J Radiat Oncol Biol Phys 34(3): 555-564.

Roach M, Bae K, Speight J, Wolkov HB, Rubin P, Lee RJ, Lawton C, Valicenti R, Grignon D, Pilepich MV (2008) Short-term neoadjuvant androgen deprivation therapy and external-beam radiotherapy for locally advanced prostate cancer: long-term results of RTOG 8610. J Clin Oncol 26(4): 585-591.

Roach III M, Hanks G, Thames Jr H, Schellhammer P, Shipley WU, Sokol GH, Sandler H (2006) Defining biochemical failure following radiotherapy with or without hormonal therapy in men with clinically localized prostate cancer: recommendations of the RTOG-ASTRO Phoenix Consensus Conference. Int J Radiat Oncol Biol Phys 65(4): 965-974.

Salanti G, Higgins JP, Ades A, Ioannidis JP (2008) Evaluation of networks of randomized trials. Statist Methods Med Res 17(3): 279-301.

Salanti G, Marinho V, Higgins J (2009) A case study of multiple-treatments meta-analysis demonstrates that covariates should be considered. J Clin Epidemiol 62(8): 857-864.

Sathya JR, Davis IR, Julian JA, Guo Q, Daya D, Dayes IS, Lukka HR, Levine M (2005) Randomized trial comparing iridium implant plus external-beam radiation therapy with external-beam radiation therapy alone in nodenegative locally advanced cancer of the prostate. J Clin Oncol 23(6): 1192-1199.

Shipley WU, Verhey LJ, Munzenrider JE, Suit HD, Urie MM, McManus PL, Young RH, Shipley JW, Zietman AL, Biggs PJ (1995) Advanced prostate cancer: the results of a randomized comparative trial of high dose irradiation boosting with conformal protons compared with conventional dose irradiation using photons alone. Int J Radiat Oncol Biol Phys 32(1): 3-12.

Siegel R, Naishadham D, Jemal A (2013) Cancer statistics, 2013. CA Cancer $J$ Clin 63(1): 11-30.

Spiegelhalter DJ, Best NG, Carlin BP, Van Der Linde A (2002) Bayesian measures of model complexity and fit. J Royal Statist Soc B 64(4): 583-639.

Storey MR, Pollack A, Zagars G, Smith L, Antolak J, Rosen I (2000) Complications from radiotherapy dose escalation in prostate cancer: preliminary results of a randomized trial. Int J Radiat Oncol Biol Phys 48(3): 635-642.

Strigari L, Arcangeli G, Arcangeli S, Benassi M (2009) Mathematical model for evaluating incidence of acute rectal toxicity during conventional or hypofractionated radiotherapy courses for prostate cancer. Int J Radiat Oncol Biol Phys 73(5): 1454-1460.
Trikalinos TA, Ioannidis J (2001) Predictive modeling and heterogeneity of baseline risk in meta-analysis of individual patient data. J Clin Epidemiol 54(3): 245-252.

Viani GA, Stefano EJ, Afonso SL (2009) Higher-than-conventional radiation doses in localized prostate cancer treatment: a meta-analysis of randomized, controlled trials. Int J Radiat Oncol Biol Phys 74(5): 1405-1418.

Yeoh EE, Botten RJ, Butters J, Di Matteo AC, Holloway RH, Fowler J (2011) Hypofractionated versus conventionally fractionated radiotherapy for prostate carcinoma: final results of phase III randomized trial. Int J Radiat Oncol Biol Phys 81(5): 1271-1278.

Yeoh EE, Fraser RJ, McGowan RE, Botten RJ, Di Matteo AC, Roos DE, Penniment MG, Borg MF (2003) Evidence for efficacy without increased toxicity of hypofractionated radiotherapy for prostate carcinoma: early results of a Phase III randomized trial. Int J Radiat Oncol Biol Phys 55(4): 943-955.

Yeoh EE, Holloway RH, Fraser RJ, Botten RJ, Di Matteo AC, Butters J, Weerasinghe S, Abeysinghe P (2006) Hypofractionated versus conventionally fractionated radiation therapy for prostate carcinoma: updated results of a phase III randomized trial. Int J Radiat Oncol Biol Phys 66(4): 1072-1083.

Zagars GK, Johnson DE, von Eschenbach AC, Hussey DH (1988) Adjuvant estrogen following radiation therapy for stage $\mathrm{C}$ adenocarcinoma of the prostate: long-term results of a prospective randomized study. Int $\mathrm{J}$ Radiat Oncol Biol Phys 14(6): 1085-1091.

Zietman AL, Bae K, Slater JD, Shipley WU, Efstathiou JA, Coen JJ, Bush DA, Lunt M, Spiegel DY, Skowronski R (2010) Randomized trial comparing conventional-dose with high-dose conformal radiation therapy in early-stage adenocarcinoma of the prostate: long-term results from Proton Radiation Oncology Group/American College of Radiology 95-09. J Clin Oncol 28(7): 1106-1111.

Zietman AL, DeSilvio ML, Slater JD, Rossi Jr CJ, Miller DW, Adams JA, Shipley WU (2005) Comparison of conventional-dose vs high-dose conformal radiation therapy in clinically localized adenocarcinoma of the prostate. JAMA 294(10): 1233-1239.

This work is published under the standard license to publish agreement. After 12 months the work will become freely available and the license terms will switch to a Creative Commons AttributionNonCommercial-Share Alike 3.0 Unported License.

Supplementary Information accompanies this paper on British Journal of Cancer website (http://www.nature.com/bjc) 